\title{
The Development of Interests in Children with Autism: A Method to Establish Baselines for Analyses and Evaluation
}

\author{
SHAHLA ALA'I-ROSALES AND NICOLE M. ZEUG, THE UNIVERSITY OF NORTH \\ TEXAS AND TANYA Y. BAYNHAM, UNIVERSITY OF KANSAS
}

By definition, children with autism have limited interests. While considerable efforts have been directed toward the social and communication difficulties faced by children with autism, less attention has been directed towards understanding the development and acquisition of new interests. Such understanding may help autism interventionists establish increasingly diverse and complex interests thereby increasing reinforcing events, learning opportunities, activity participation, and social engagement. This paper describes an observational system for monitoring reinforcer diversity and event engagement during naturalistic teaching portions of an early intervention program. Data are presented for two children. It is suggested that such measures are necessary for two reasons. First, given the lack of empirical support and the importance of reinforcers, there is a need for measurement systems to monitor the development of interests in early intervention programs for children with autism. Second, there is a paucity of research addressing expansion of interests. Developing measurement systems increases the likelihood that evidence-based practices will emerge. Hopefully, these efforts will increase our knowledge, increase child preference for instruction, and open avenues for enhanced instructional and life opportunities based on expanded interests.

By definition, children with autism have restricted activities and interests and appear to be motivated by a limited number of unusual events rather than motivated by the wide variety of events common to their peers without disabilities (American Psychiatric Association, 2000). It has long been recognized that the limited or unusual motivation observed in children with autism is a central concern having implications for intervention and for long-term outcome (e.g., Lovaas, et al., 1966; Ferster, 1961; Koegel \& Egel, 1979). The purpose of this paper is to provide rationales for expanding the interests of children within early intervention programs, to highlight promising practices for expanding interests, and to offer a preliminary method for establishing baselines that capture the development of interests and allow practitioners to objectively evaluate the effects of their efforts to diversify the interests of the children they serve.

\section{THE IMPORTANCE OF DIVERSE INTERESTS AND ACTIVITIES}

Many child development theories, including behavioral systems theories, suggest that one of the ways children develop is through their engagement in play and through their continuously expanding interests, allowing contact with new environmental stimuli that result in further potential for increased knowledge and advanced skill repertoires (Novak \& Peláez, 2004). In fact, when introducing the concept of acquired reinforcers, Novak and Peláez suggest that, "It is partly the unique set of reinforcers a person acquires that determines that person's special repertoire of behaviors (pp. 194, 2004)." In other words, our behaviors appear to be strongly tied to our interests or preferences for events. One conceptual and pragmatic model for understanding the effects of varied interests on children is the "behavioral cusp" (Rosales-Ruiz \& Baer, 1997). The term behavioral cusp describes the outcomes of any behavior-change procedure that produces broad, pervasive, or especially important changes in the child's environments, reinforcers or opportunities. Increased rates and diversification of interests and the subsequent opportunities that emerge could be viewed as behavioral cusps in children with autism (Ala'i-Rosales, Smith, \& EldenSmith, 2008). At the most fundamental level it is 
possible that understanding how to increase the diversity and number of interests in children with autism can have important implications for their overall development, ranging from occupying one's time in safe and productive ways to having meaningful activities to share with loved ones. Furthermore, as interventionists, one of our primary instructional tools is the systematic and careful arrangement of reinforcing events (e.g., Anderson \& Romancyk, 1999; Cooper, Heron, \& Heward, 2007). This can become challenging when the learner has a limited number of interests.

In summary, the benefits of monitoring and developing new and diverse reinforcers, especially related to social attention, would be useful in all teaching environments and may foster important and pervasive changes in the child's overall development.

\section{THE DEVELOPMENT OF NEW INTERESTS}

Although there has been a considerable body of autism intervention research directed towards understanding the variables that produce the development of verbal behavior (c.f., Goldstien, 2002) and social behavior (c.f., McConnell, 2002), there is limited information about how to produce new interests (e.g., Wolery \& Garfinkle, 2002; Wolery, Barton, \& Hine, 2005). This area, however, has received attention in research regarding diagnostic classification and definition. In the 2005 edition of the Handbook of Autism, Chawarska and Volkmar (2005) provide an overview of the research aimed at understanding the developmental differences between very young children with autism and children without autism. Although the research is emerging and there are methodological limitations, Chawarska and Volkmar (2005) summarized several areas that may be important markers for the development of measures and procedures to expand interests. For example, in the first year of life children with autism are less likely than typically developing children to look at objects held by others, have little interest in interactive games that other children enjoy; in the second and third years of life children with autism engage in little functional play and no pretend play, are not likely to share an interest with another person, are more likely to use objects in unusual and repetitive ways not observed in their nondisabled counterparts, and engage in little functional play and no pretend play (pp. 230). In addition to helping basic researchers understand the nature of autism, these data can inform applied researchers and early interventionists. For example, if low rates of interactive games and pretend play and high rates of solitary activity and preservation are common in young children with autism, then an early interventionists/applied researchers may want to develop procedures (and systems to evaluate the effectiveness of the procedures) to increase interactive games, pretend play and the diversity of activity engagement.

\section{INTERESTS EXPANSION GOALS IN EARLY INTENSIVE BEHAVIORAL INTERVENTION (EIBI) PROGRAMS}

EIBI Outcome Research. Although there are variations in configurations, delivery and emphasis, the current goals of behavioral early intervention are quite similar and consistent. That is, EIBI research demonstrations that describe their curricula (and books based on those research procedures) stress several skill areas of importance: learning to learn (imitation, observing, listening); communication and language; social and play; self help; and academics (e.g., Lovaas, 1981/2003; Leaf \& McEachin, 1999; Howard, et al., 2005; Maurice, Green, \& Luce, 1996; Maurice, Green, \& Fox, 2001; Smith, Groen, \& Wynn, 2000). None of these descriptions directly address conditioning new interests or providing measures to evaluate the development of interests. And with a few exceptions (Leaf \& McEachin,1999; Ahearn, 2001), none offer extensive programming or procedures for systematically increasing the diversity and complexity of high preference activities. It may be the case that for 
some children, the total intervention package creates conditions that result in activities and interests similar to their peers without autism; or it may not be the case. Without any systematic measures to allow analysis or evaluation it is not clear what, if anything, changes. Although the expansion of interests has not been a central consideration in EIBI, there is an emerging body of procedural suggestions and some preliminary research.

\section{PROCEDURAL SUGGESTIONS AND PROMISING PRACTICES.}

There are no practices for systematically establishing and expanding new interests that would meet any established criteria for an "evidence-based practice." That is, there are no well controlled studies that that have been replicated with multiple children, by multiple research laboratories (for various research evaluation criteria, see Green, 1996; Horner et al. , 2005; Dunst, Trivette, \& Cutspec, 2002). There are a few books that offer suggestions for increasing the play and leisure skills in children with autism (e.g., Coyne, Nyberg, \& Vandenburg, 1999; Wolfburg, 1999) and a growing body of promising research on teaching plays skills (c.f., Stahmer, Ingersoll, \& Carter, 2003). It is important to note, however, that unless a preference or reinforcer assessment is conducted the taught "play skill" may not actually be "play" as the term is typically defined. Most agree that play means the child chooses the activity, in the absence of programmed prompts or consequences, and has positive affect while engaged in the activity (c.f., Rogers, Cook \& Meryl, 2005)). Although some studies have anecdotally reported increased preference and acceptance (e.g., Cameron, Shapiro, \& Ainsleigh, 2005), there are no studies that appear to teach play skills and that also formally assess preference or reinforcing function of these newly acquired skills.

In addition to increasing the number and diversity of play activities, interests can be expanded in other ways. Again, this body of research in no way constitutes "evidence based practice" but does offer practitioners promising starting points based on conceptual analyses or basic research. For example, procedures to modify children's tolerance and acceptance of sensory stimuli has been addressed in a limited number of studies (e.g., Ellis, et al, 2005; Keogel, Openden \& Koegel, 2004; Love, Matson \& West, 1990); expansion of children's food preferences has been addressed in a few studies (c.f., Ahearn, 2001); there are a number of studies analyzing the effects of setting event manipulations on preferences that may have direct bearing on expanding the interests of children with autism (e.g., Charlop-Christy \& Haymes, 1998; Dunlap \& Koegel, 1980; Hanely, Iwata, \& Lindberg, 1999; Klatt, Sherman, \& Sheldon, 2000) and, finally, methods to directly condition new events have sporadically appeared in the literature (e.g., Adroin, et al., 2004; Nuzzolo-Gomez, 2002), the most notable being Lovaas' early efforts to establish social attention as a reinforcer (1966).

In summary, the proposed goals in expanding interests and activities in EIBI are two-fold: 1 ) to increase the number of events that function as reinforcers in order to improve the quantity and quality of our instruction and to 2) help establish an ever increasing number of events that hold interest and increased life opportunities for happiness and discovery for the child with autism. As interventionists serving young children with autism we have several legal and/or ethical mandates (e.g., IDEA, BACB Guidelines for Ethical Conduct) that oblige us to measure socially important goals and to evaluate the efforts of our interventions on those goal behaviors.

\section{CREATING MEASURES OF EMERGING "INTERESTS" IN EIBI PROGRAMS}

To the best of our knowledge there is no EIBI measurement system designed for continuous of assessment of children's developing interests (number, novelty, and diversity). Because our purpose was to create an observational system 
that captures changing "interests", the literature on preference and reinforcer assessment and the literature maximizing motivation in natural environment teaching, informed the development of our observation protocols. The research on preference and reinforcer assessment is robust (c.f., Cooper, Heron, \& Heward, 2007; Hagopian, Long, \& Rush, 2004) and offers several useful methods, such as the importance of frequent assessment and the changing nature of what will function as a reinforcer or interest during any given set of stimulus conditions (e.g., Mason, McGee, Farmer-Dougan, \& Risley, 1989) and the utility of observing children's specific preferences through direct observation of engagement under freeplay conditions (e.g. Reid, DiCarlo, Schepis, Hawkins \& Stricklin, 2003). The research on the use of motivation in naturalistic teaching (c.f, Delprato, 2001; Keogel \& Koegel, 2006; Noonan \& McCormick, 2007) was also useful in that functional communication training was a target for both of the children described here and one of the first ways we began to measure interests was during request, or "mand", training; our presumption was that if they communicated for it, it was probably a preference, an interest.

The measurement systems described and presented here were developed to help teams evaluate the levels and trends of interests of the children with autism enrolled in the campus early intervention program. As with most children with autism, the children in the two case examples presented here started in the program with very limited interests.

\section{GENERAL METHOD}

\section{Participants}

Daniel and Tanner were both preschool children diagnosed with autism by diagnosticians not associated with the university early intervention program. Both children were participating in a campus early intervention program designed for young children with autism that was supervised by a
Board Certified Behavior Analyst (first author). The intervention teams consisted of the parents and graduate students in Behavior Analysis with an autism special interest emphasis. Expanded descriptions of each child are provided in each "Case Example".

\section{Settings}

Data were collected during regular intervention sessions. Sessions took place for both children at home (primarily playrooms and outdoor play areas) and in an on-campus intervention playroom.

\section{Procedures}

Goals related to the expansion of activities and interests were developed as a part of each child's comprehensive intervention program. During the course of intervention period presented here, their other teaching programs included: rapport and social approach, functional communication, motor and vocal imitation, receptive and expressive labeling, toy and social play, self-help, preacademic skills, and instruction following. During the initial phases of intervention, the emphasis was on rapport building, functional communication training and increasing engagement with activities and with others. As treatment progressed, the remaining EIBI programs described earlier were introduced. The communication training is of particular interest here since that is were the primary data indicating "interest" is obtained. We also added "expansion" treatment programs for both boys. For both Tanner and Daniel, naturalistic teaching arrangements were utilized in communication training (e.g., Hart \& Risley, 1968/1975; Kaiser, 1998; Koegel \& Koegel, 2006; McGee, Krantz \& McClannahan, 1985). Various materials were continuously available during sessions, with high preference items out of reach or in containers. Based on criterion related attempts and approximations (e.g., Koegel, O'Dell, \& Dunlap, 1988) these items were contingently provided (e.g. Saunders \& Sailer; 1979; Koegel \& Williams, 1980; Williams, 
Koegel \& Egel, 1981). For Daniel, three sets of play area toys were systematically rotated and the different sets were made available approximately every two weeks (e.g., McGee, Morrier, \& Daly, 2000).

The "expanding interest" programs for Tanner and Daniel consisted of the availability and systematic presentation of existing and novel events (toys, food, and social activities) during every intervention sessions as suggested by Coyne, Nyberg, \& Vandenburg (1999). During each session each interventionist was prompted to "bring/find about three new (novel) things" that were similar to (in terms of the presumed reinforcing properties) or different from the existing interest items for which we had data (e.g., on a given session a teacher might try playing chase, offer peaches, and present match box cars as the new events). These items were presented using a quota system (try 3 each session), were available during play periods and could potentially be requested during communication training. If either of the boys requested the item using the established response criteria it was delivered (e.g., the video was turned on if they made an approximation to the word video, such as "veeyo") and if they engaged in an event every effort was made to reinforce that engagement (e.g., handing them extra balls for the air pop game)

\section{Measures}

All data were collected during intervention sessions by in home interventionists (supervised by the second and third authors). Data were collected in two different conditions: during communication training and during play periods (these were also instructional periods but were childinitiated through event selection rather than teacher-initiated through instructions). The play periods were interspersed through about half of each 120 -minute sessions. Data were collected using paper data sheets and pencils. The total number of different events and the types of events were recorded. The specific measures and recording systems are described in each case example.

\section{Case Example 1: Tanner}

Tanner was 29 months old at the onset of intervention and lived with his mother and two older siblings. He was of Asian and Caucasian descent. Prior to intervention Tanner was diagnosed with severe and profound autism, was completely non-vocal and had no conventional means of communication. At the onset of services, he had an extremely limited number of things that he was interested in and that could potentially be used as reinforcers. With the exception of one particular video clip and opening and closing doll house doors, the other items he did select or engage with were not considered safe for him or for use during instruction (e.g., knives, cigarette carton cellophane, climbing on stoves). He received home intervention approximately $15 \mathrm{hrs}$ per week and attended a typical three hour preschool program for three mornings per week.

From the onset of services, data were collected on the items that Tanner requested during communication training. Communication training occurred throughout each intervention session, that is, as long as he was not in the middle of a teacher directed task he was free to request a high preference item. On the session's data sheet, interventionists wrote the name of the each item Tanner requested (subsequent requests for that item were tallied) and the data sheets were later analyzed by session to determine when a new item was added to the pool of requested items. For example, in early sessions when the number of interests were severely restricted he only asked for video (at first with any sound and then with an approximation to the actual word), as sessions progressed he continued to request video but might also request a "spin" in a large play disc. The first time a new item appeared (such as the disc) it was added to the novel interest list. 
Figure 1

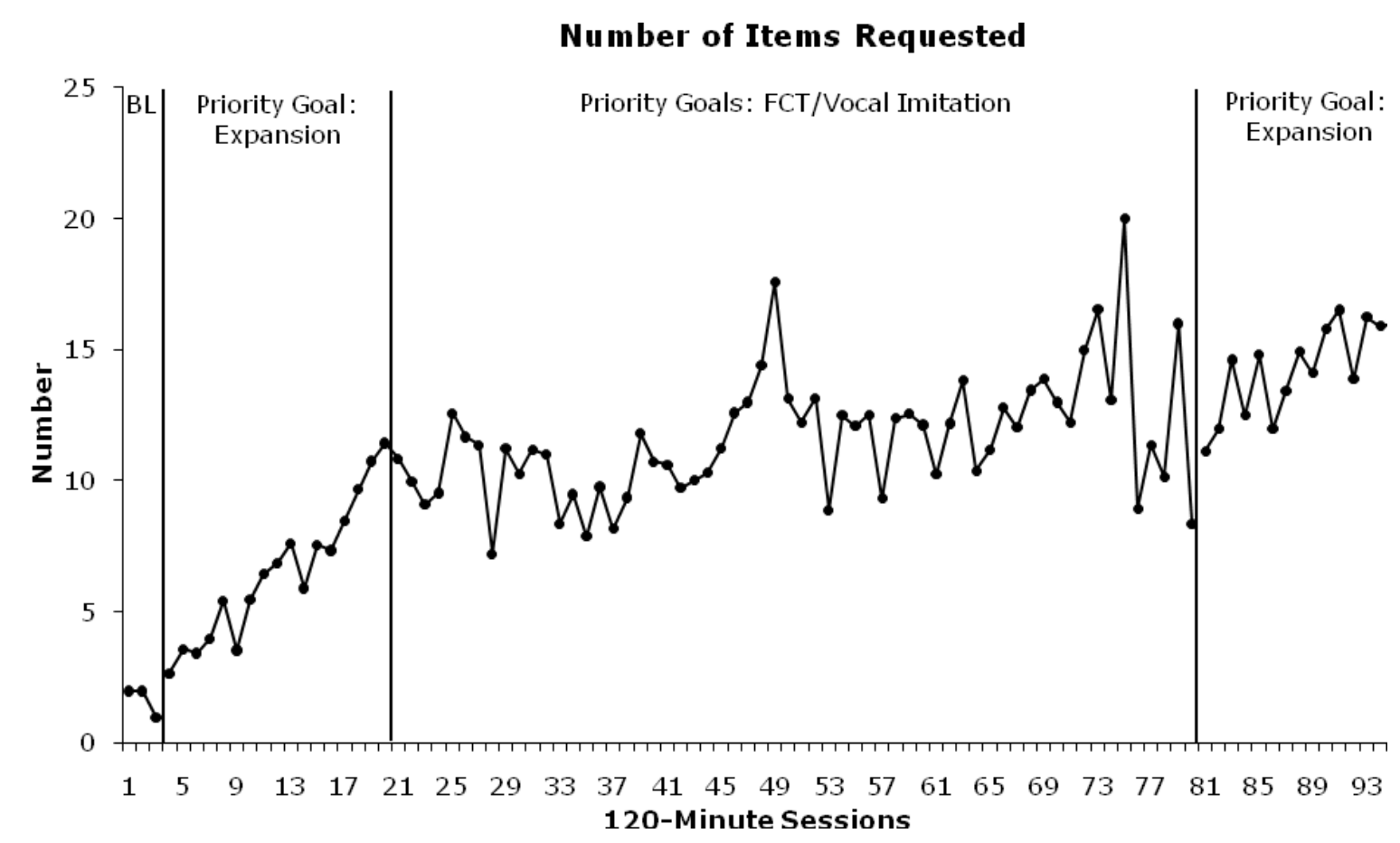

Figure 1 illustrates the number of novel items that Tanner requested over the course of 95 consecutive sessions. During the first few sessions of intervention his interests were very limited (1-3 items were requested) and the shaping of eye contact and vocalizations had just begun. Beginning in the 4th session a concerted effort (as described in the general procedures) was made to increase the number of novel events he requested. It should be noted that all the other teaching programs were also in effect, that he was learning to vocalize for access to events and the interventionists were also becoming better shapers. During this period (sessions 4-20) the number of novel items requested rose dramatically, from 3 items to 12 items. After this period, and in part because we were satisfied with the steady and consistent increase in novel events, the emphasis of his program shifted to imitations and increasing the intelligibility of the words he was using to request. Although interventionists still introduced new items and the events were recorded, it was not considered a priority program again until session 81 . At that time the program priority was on teaching play skills. Throughout these last two periods he continued to request novel events but not at the same rate of change as in the first period.

After observing the benefits of this additional measure to the battery of data in an early intervention program and evaluating variables that might be of importance, we considered modification to the behaviors we were counting. For the next participant, we continued counting the number of new events requested during communication training but added additional measures.

\section{Case Example 2: Daniel}

At the time services began Daniel was also a 29-month-old and diagnosed with autism. He was of Hispanic and Caucasian descent and lived at home with his mother and father. Upon entry he exhibited some eye contact, had some vocal approximations to words, and simple cause-effect play skills with a moderate number of toys (his mother had taught many of these skills through the campus parent training program). He had no imitation skills, 
conventional communication skills, and would only attend to activities for a minute before moving on to the next event. He was a very active toddler who loved to run around in circles and up and down hallways. He also liked to repeatedly put small objects inside larger objects and to line objects up in rows. The clinic-based therapy took place in a playroom, outside, and in the hallways (he liked playing chase down the long corridors). He received about 25 hours per week of intervention. At the onset of intervention, Daniel had a limited number of items that he would engage with and frequently would not engage with novel items. Therefore, as with Tanner, data were collected on a number of novel events requested. However, several issues arose in our analysis of Tanner's data: What was the cumulative number of events over the course of the analysis? Was he consistently being presented with novel items by the staff (even when this was not a priority program)? Did he become increasingly more accepting of novel items? Were there differences in the development of different classes of items? And, did the communication data just reflect learning to request all the items he was already interested in but had no means to access? Would unprompted engagement data reflect different patterns in comparison to the communication data? For those reasons, additional measures and analyses were added for the next child, Daniel, we served.

We looked at both the number of requests for new items requested but we also counted the cumulative number of new events, the types of events and the number of events sampled and rejected. New events sampled were defined as a novel stimulus that he engaged with, touched or manipulated, for more than $2 \mathrm{~s}$ upon presentation. New events rejected were defined as presented stimuli that he did not touch or manipulate for more than $2 \mathrm{~s}$. New events sampled/rejected were separated as toys, social or edibles. Items requested were defined as toys, social or edibles that he requested during functional communication training in the form of vocal approximations.

Figure 2 displays the cumulative number of different events requested during communication training and the number of the new events sampled and rejected, both separated by toys, social and edibles, across $96,120-\mathrm{min}$ ( $2 \mathrm{hr}$ ) sessions. The cumulative increase of the data path for total items engaged with and separated by stimuli type is higher initially and decreases starting around the 53rd session. This was around the time we began to focus on more teacher initiated instruction. The majority of the new events were different toys and a few of the new events were social activities (e.g., tickle games). Very few of the new events were edibles which may have had to do with his very restricted interests in foods (that were later addressed) and because toy play seemed an appropriate type of event to increase during play and communication interactions. Figure 3 contains an analysis of the cumulative new events independently engaged and rejected during play periods and are organized by total events (top graph) and by type (2nd and 3rd graphs). The overall numbers are higher than in communication training (items requested) but do not have the same sharp slopes, but rather a steady increase over the course of the period of observation. As was observed in the requesting conditions, new toys were offered and accepted more often than edibles or socials.

Furthermore the proportion of engagement was higher than rejections.

\section{GENERAL DISCUSSION}


Our purpose was to develop measures that would reflect changes in interests, as indicated by requests and engagement. Both boys showed increases in the number of new events requested throughout the intervention period reported here. With further measures, we were able to observe similar increases in the number of events engaged in as well as observe differences in the types of events for the second child, Daniel. It was clear from analysis of the

Figure 2

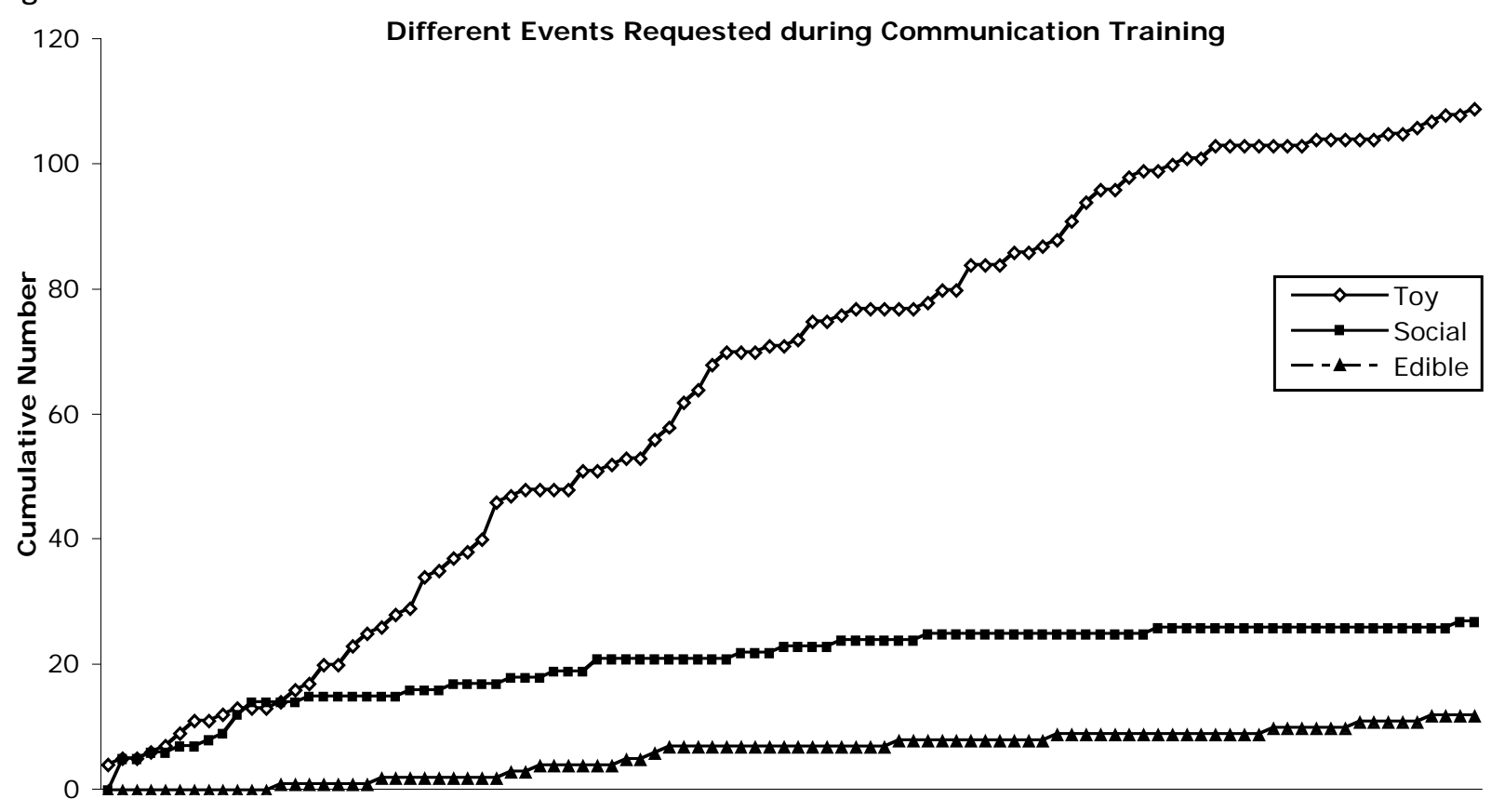

New Events Requested during Communication Training

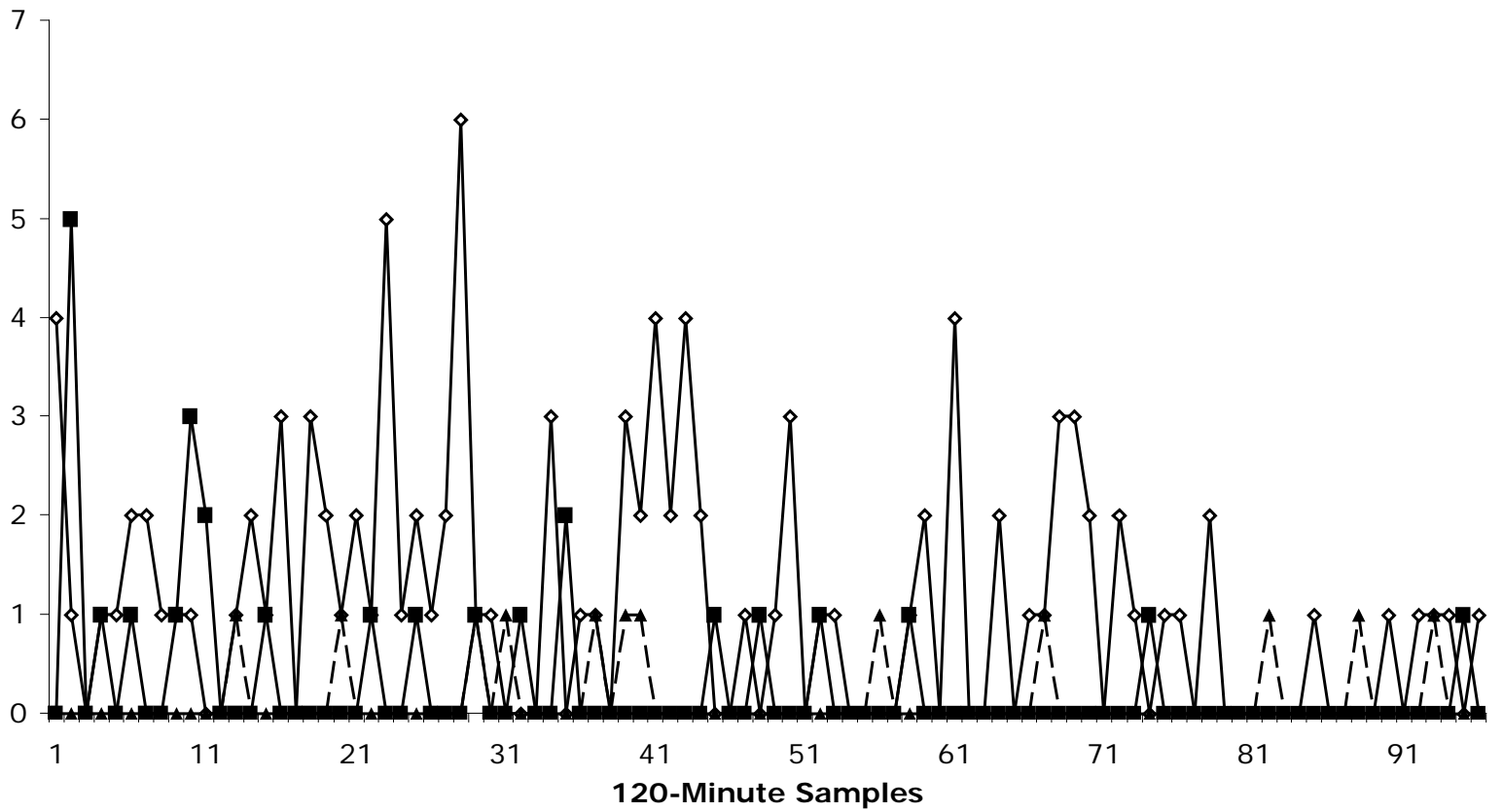


data that we were making progress in terms of his toy play, but social events and diverse edible items should be priorities for future interventions. As we learned from Tanner's data collection and analysis, we also learned from Daniel's. Future efforts will add indices of happiness or enjoyment (eg. Green \& Reid, 1996), one of the criteria for an event to actually be considered "play" (e.g., Rogers, Cook \& Meryl, 2005) as it appeared at times during the engagement counts that Daniel engaged in activities without pleasant affect and that it may have been likely that he was avoiding other activities rather than attracted to the event itself. Additionally, we observed that some of the activities remained constant but that what he did with the materials increased in complexity. Future systems should incorporate some kind of method for recording changes in the actions as has been suggested by researchers specializing in play skill instruction (e.g., Lifter, Ellis, Cannon \& Anderson, 2005).

The addition of such measures presents challenges for practitioners in that data collection typically occurs during instruction (as in the present analysis) and additional data collection can be cumbersome. The benefits, however, may warrant gathering of such information.

If theorists are correct (Novak \& Peláez, 2004) in that play and diverse reinforcers are important for future development then it follows that we should begin to study the development of interests and activities. The systematic collection of this information will aid in increasing the diversity of reinforcers available for effective teaching interactions and help us begin to understand what factors account for changes in the activity of children with autism, especially those changes that appear to be behavioral cusps (Rosales-Ruiz \& Baer, 1997).

Our intent was not to imply nor demonstrate a functional relationship between the observed changes and the increase in events that appear to be new interests. It is possible that the "expansion programs" (based on the promising practices described earlier) we implemented could have contributed to the observed increases. Other factors, however, are likely. Both boys were in an early intervention program that involved intensive systematic skill instruction. The literature reports that the outcomes of these types of instruction can produce groups of behaviors that are similar their typically developing peers (e.g., Fenske, Zalenski, Krantz \& McClannahan, 1985; Lovaas, 1987; Koegel, Koegel, Harrower, \& Carter,1999; Wolf, Risley \& Mees, 1964). Presumably, those children, after treatment, displayed more typical types and ranges of interests. It is quite likely that something about the constellation and delivery of the EIBI interventions accounts for the changes in interests. At the same time, not all children have such favorable outcomes and it is possible that the continuation of restricted activities and interests may play a role. However, without measures it is impossible to know what the nature and course of the changes were and if the data presented here are similar or different than what occurs in other early intervention packages with children that enter treatment with similar or different skills and interests. Which is part of our point. Unlike the areas of social and communication skills, there is very little guidance available regarding the development of interests. We need measurement tools to help us understand the changes. 
Figure 3
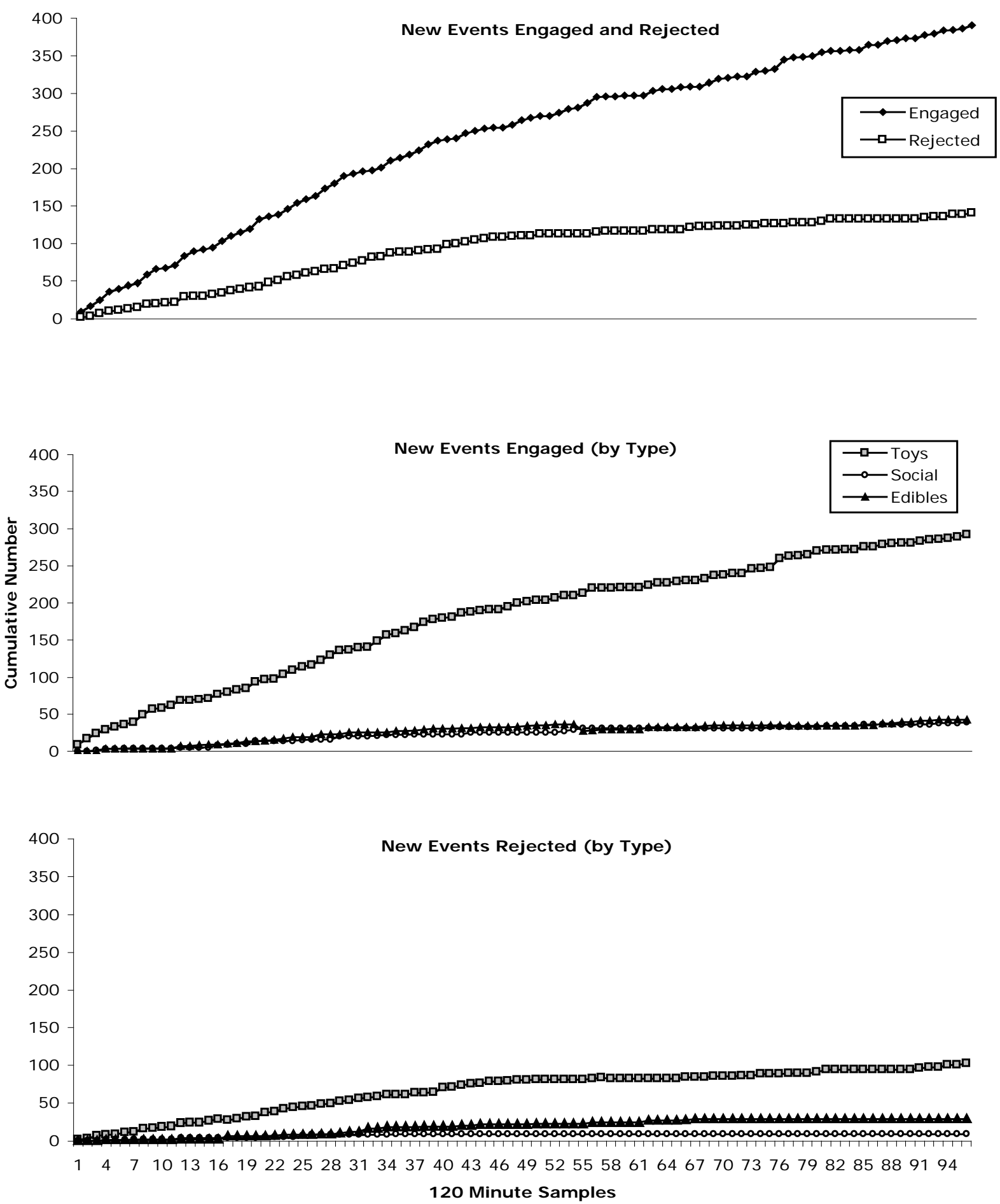

This paper presents a preliminary attempt to develop a measurement system that allows observation of changes. It is our hope that this is methodological contribution serves as a stimulus for practitioners and researchers to understand more about acquired interests, 
especially in children with autism. Such a system would be useful to interventionists for two reasons. First, given the limited information as to how new interests develop and the paucity of evidence-based practices to stimulate that development, interventionists are obliged to measure in order to develop and evaluate their own procedures for expanding and maintaining a diverse and rich array of interests in the children they serve. Second, in doing so the likelihood that evidence-based practices will emerge is increased. The beloved Todd Risely asked, "Do you have enough tools to see reality clearly and change it for the better? You will never know unless you try (pp. 234, 2001)." This is one attempt to expand the toolbox of those serving children with autism. Hopefully, these efforts will help increase our knowledge of acquired interests, increase child preference for instruction, and open avenues for enhanced instructional and life opportunities.

\section{References}

Ahearn, W.H. (2001). Help! My son only eats macaroni and cheese: Dealing with feeding problems in children with autism. In: Maurice, C., Green, G., \& Foxx, R. M. (Eds.) Making a difference. Austin, TX: Pro-Ed.

Ala'i-Rosales, S. Smith, G., Eleden-Smith, P. (2008). Behavioral cusps as a conceptual model and a curricular guidepost: Stories of person-centered changes across the spectrum. Manuscript submitted for publication.

American Psychiatric Association (2000). Diagnostic and statistical manual of mental disorders V. Washington, D.C.: American Psychiatric Association.

Anderson, S.R., \& Romanczyk, R.G. (1999). Early intervention for young children with autism: Continuum-based behavioral models. Journal of the Association for Persons with Severe Handicaps, 24, 162-173.

Ardroin, S. P., Martens, B. K., Wolfe, L. A., Hilt, A. M., \& Rosenthal, B. D. (2004). Journal of Developmental and Physical Disabilities, 16(1), 33-51.

Behavior Analyst Certification Board. (2004). Behavior Analyst Certification Board guidelines for responsible conduct for behavior analysts. Retrieved February 8th, 2008 from http://www.bacb.com/pages/conduct. html

Cameron, M J., Shapiro, R. L., \& Ainsleigh, S. A. (2005). Bicycle riding: Pedaling made possible through positive behavioral interventions. Journal of Positive Behavioral Interventions, 7(3), 153158.

Charlop-Christy, M.H., \& Haymes, L.K. (1998). Using objects of obsession as token reinforcers for children with autism. Journal of Autism and Developmental Disorders, 28, 189-198. Chawarska, K. \& Volkmar, F. R. (2005). Autism in infancy and early. In: Volkmar, F.R., Paul, R., Klin, A., \& Cohen, D. (Eds.) Handbook of autism and pervasive developmental disorders, Vol. 1: Diagnosis, development, neurobiology, and behavior (3rd ed. pp. 223-246). Hoboken, NJ, US: John Wiley \& Sons Inc.

Cohen, H., Amerine-Dickens, M., \& Smith, T. (2006). Early intensive behavioral treatment: Replication of the UCLA model in a community setting. Journal of Developmental \& Behavioral Pediatrics, 27(2), 145-155.

Cooper, J.O., Heron, T.E., \& Heward, W.L. (2007). Applied Behavior Analysis (2nd ed.). Columbus, $\mathrm{OH}$ : Merrill Publishing.

Coyne, P., Nyberg, C., \& Vandenburg, M. (1999). Developing leisure time skills for persons with autism. Arlington, TX: Future Horizons, Inc.

Delprato, D. J. (2001). Comparisons of discretetrial and normalized behavioral language intervention for young children with autism. Journal of Autism \& Developmental Disorders, 31(3), 315-325.

Dunlap, G., \& Koegel, R. L. (1980) Stimulus variation and motivation in autistic children. Journal of Applied Behavior Analysis, 13, 619-627.

Dunst, C. J., Hamby, D., \& Trivette, C. M. (2000). Everyday family and community life and children's naturally occurring learning opportunities. Journal of Early Intervention, 23(3), 151-164.

Eikeseth, S. Smith, T., Jahr, E., \& Eldevik, S. (2002). Intensive behavioral treatment at school for 4 to 7 year old children with autism. Behavior Modification, 26, 49-68. 
Ellis, E.M., Ala'i-Rosales, S.S., \& Glenn, S.S. (2006). The effects of graduated exposure, modeling, and contingent social attention on tolerance to skin care products with two children with autism. Research in Developmental Disabilities, 27(6), 585-598.

Fenske, E.C., Zalenski, S., Krantz, P.J., \& McClannahan, L.E. (1985). Age at intervention and treatment outcomes for autistic children in a comprehensive intervention program. Analysis and Intervention in Developmental Disabilities, 5, 49-58.

Ferster, C. (1961). Positive reinforcement and behavioral deficits of young children. Child Development, 32, 437-456.

Green, G. (1996). Evaluating claims about treatments for autism. In: Behavioral intervention for young children with autism: A manual for parents and professionals. Maurice, C., Green, G., \& Luce, S. C. (pp. 29-44). Austin, TX: ProEd.

Goldstein, H. (2002). Communication interventions for children with autism: A review of treatment efficacy. Journal of Autism and Developmental Disorders, 32, 373-396.

Green, G., Brennan, L. C., \& Fein, D. (2002). Intensive behavioral treatment for a toddler at high risk for autism. Behavior Modification, 26, 69-102.

Green C.W, \& Reid D.H. (1996) Defining, validating, and increasing indices of happiness among people with profound multiple disabilities. Journal of Applied Behavior Analysis. 29, 6778.

Hagopian, L. P., Long, E. S., \& Rush, K. S. (2004). Preference assessment procedures for individuals with developmental disabilities. Behavior Modification, 28(5), 668-677.

Hanley, G. P., Iwata, B. A., \& Lindberg, J. S. (2003). Analysis of activity preferences as a function of differential consequences. Journal of Applied Behavior Analysis, 32, 419-435.

Hart, B.M., \& Risley, T.R. (1968). Establishing the use of descriptive adjectives in the spontaneous speech of disadvantaged preschool children. Journal of Applied Behavior Analysis, 1, 109120.

Hart, B.M., \& Risley, T.R. (1975). Incidental teaching of language in the preschool.
Journal of Applied Behavior Analysis, 8, 411-420.

Horner, R. H., Carr, E. G., Halle, J., McGee, G., Odom, S., \& Wolery, M. (2005). The use of single-subject research to identify evidence-based practice in special education. Exceptional Children, 71(2), 165-179.

Howard, J.S., Sparkman, C.R., Cohen, H.G., Green, G., \& Stanislaw, H. (2005). A comparison of intensive behavior analytic and eclectic treatments for young children with autism. Research in Developmental Disabilities, 26, 359383.

Kaiser, A. P. (1998). Teaching functional communication skills. In M. E. Snell (Ed.),

Instruction of students with severe disabilities (5th ed., pp. 453-492). New York;

MacMillian.

Klatt, K. P., Sherman, J. A., \& Sheldon, J B. (2000). Effects of deprivation on engagement in preferred activities by persons with developmental disabilities. Journal of Applied Behavior Analysis, 33, 495506.

Koegel, R. L., \& Egel, A. L. (1979). Motivating autistic children. Journal of Abnormal Psychology, 88, 418-426.

Koegel, R. L., \& Koegel, L. K. (2006). Pivotal response treatments for autism. Baltimore, MD: Paul H. Brookes.

Koegel, L.K., Koegel, R.L., Harrower, J.K. \& Carter, C.M. (1999) Pivotal response intervention I \& II, Journal of the Association for Persons with Severe Handicaps, 24, 174-198

Koegel, R. L., O’Dell, M., \& Dunlap, G. (1980). Producing speech use in nonverbal autistic children by reinforcing attempts. Journal of Autism and Developmental Disorders, 18 , 525-538.

Koegel, R. L., Openden, D., \& Koegel, L. K. (2004). A systematic desensitization paradigm to treat hypersensitivity to auditory stimuli in children with autism in family contexts. Research \& Practice for Persons with Severe Disabilities, 29(2), 122-134.

Koegel, R. K., \& Williams, J. A. (1980). Direct vs. indirect response-reinforcer relationships in teaching autistic children. Journal of Abnormal Child Psychology, 8, 537-547. 
Leaf, R., \& McEachin, J. (1999). A Work In Progress. New York: DRL Books.

Lifter, K., Ellis, J., Cannon, B., Anderson, S. R. (2005). Developmental specificity in targeting and teaching play activities to children with pervasive developmental disorders. Journal of Early Interventions, 27(4), 247-267.

Lovaas, O. I., Freitag, G., Kinder, M. I., Rubenstein, B. D., Schaefer, B., \& Simmons, J. Q.(1966). Establishment of social reinforcers in two schizophrenic children on the basis of food. Journal of Experimental Child Psychology, 4, 109-125.

Lovaas, O. I. (1981). Teaching Developmentally Disabled Children. Austin: Pro-ed.

Lovaas, O.I. (1987). Behavioral treatment and normal educational and psychological functioning in young autistic children. Journal of Counseling and Clinical Psychology, 55, 3-9.

Lovaas, O. I. (2003). Teaching individuals with developmental delays. Austin, TX: ProEd.

Love, S. R., Matson, J. L., \& West, D. (1990). Mothers as effective experimenter's for autistic children's phobias. Journal of Applied Behavior Analysis, 23, 379385.

Mason, S. A., McGee, G. G., Farmer-Dougan, V., \& Risley, T. R. (1989). A Practical strategy for ongoing reinforcer assessment. Journal of Applied Behavior Analysis, 22, 171-179.

Maurice, Green, \& Luce (1996). Behavioral Interventions for Young Children with Autism. Austin: Pro-ed.

Maurice, Green \& Foxx (2001). Making a Difference. Austin: Pro-ed.

McConnell, S. (2002). Interventions to facilitate social interaction for young children with autism: Review of available research and recommendations for educational intervention and future research. Journal of Autism and Developmental Disorders, 32(5), 351373.

McEachin, J. J., Smith, T., \& Lovaas, O. I. (1993). Long-term outcome for children with autism who received early intensive behavioral treatment. American Journal on Mental Retardation, 97, 359-372.

McGee, G. G., Krantz, P. J., \& McClannahan, L. E. (1985). The facilitative effects of incidental teaching in prepositional use by autistic children. Journal of Applied Behavior Analysis,

18, 17-31.

McGee, G., Morrier, M.J., \& Daly, T. (2000). The Walden early childhood programs. In: Handleman, J.S., \& Harris, S. L. (Eds.). Preschool education programs for children with autism (2nd Edition, pp. 157-190). Austin, TX: Pro-Ed.

Noonan, M., \& McCormick, L. (2006). Young children with disabilities in natural environments: Methods and procedures. Baltimore, MD: Paul $\mathrm{H}$. Brookes Publishing Co.

Novak, G. \& Pelaez, M. (2004). Child and Adolescent Development: A Behavioral Systems Approach. Thousand Oaks, CA: Sage Publications.

Nuzzolo-Gomez, R., Leonard, M. A., \& Ortiz, E. (2002). Teaching children with autism to prefer books or toys over stereotypy or passivity. Journal of Positive Behavioral Interventions, 4(2), 80-87.

Reid, D.H., DiCarlo, C.F., Shepis, M.M., Hawkins, J., \& Stricklin, S.B. (2003).

Observational assessment of toy preferences among young children with disabilities in inclusive settings: Efficiency analysis and comparison with staff opinion. Behavior Modification, 27, 233-250.

Rogers, S. J., Cook, I., \& Meryl, A. (2005). In: Volkmar, F.R., Paul, R., Klin, A., and Cohen, D. (Eds.), Handbook of autism and pervasive development disorders (pp. 5-41). Hoboken, NJ: John Wiley \& Sons, Inc.

Risley, T. (2001). Do good and take data. In: O'Donohue, W. T., Henderson, D. A., Hayes, S.C., Fisher, J. E., \& Hayes, L. J. (Eds.), A history of the behavioral therapies: Founders personal histories (pp. 223-243). Reno, NV: Context Press.

Rosales-Ruiz, J., \& Baer, D. M. (1997). Behavioral cusps: A developmental and pragmatic concept for behavior analysis. Journal of Applied Behavior Analysis, 30, 533544.

Sallows, G. O., \& Graupner, T. D. (2005). Intensive behavioral treatment for children with autism: Four-year outcome and predictors. American Journal on Mental Retardation, 110 (6), 417-438.

Saunders, R. \& Sailer, W. (1979). A comparison of three strategies of reinforcement on 
two-choice language problems with severely retarded children. AAESPH Review, 4, 323-333.

Smith, T., Groen, A. D., \& Wynn, J. W. (2000). Randomized trial of intensive early intervention for children with pervasive developmental disorder. American Journal on Mental Retardation, 105, 269-285.

Stahmer, A.C., Ingersoll, B., \& Carter, C. (2003). Behavioral approaches to promoting play. Autism-International Journal of Research and Practice, 7, 401-413.

Turnbull, III, H. R. (2005). Individuals with disabilities education act reauthorization: Accountability and personal responsibility. Remedial \& Special Education, 26(6), 320-326.

Williams, J. A., Koegel, R. K., \& Egel, A. L. (1981). Response-reinforcer relationships and improved learning in autistic children.
Journal of Applied Behavior Analysis, 14, 53-60.

Wolery, M., Barton, E. E., Hine, J. F. (2005). Evolution of applied behavior analysis in the treatment of individuals with autism. Exceptionality,13(1), 11-23.

Wolery, M., \& Garfinkle, A. N. (2002). Measures in intervention research with young children who have autism. Journal of Autism and Developmental Disorders, 32, 463-478.

Wolf, M.M., Risley, T.R., \& Mees, M. (1964). Application of operant conditioning procedures to behavior problems of an autistic child. Behavior Research and Therapy, 1, 305-312.

Wolfberg, P. J. (1999). Play and imagination in children with autism. New York, NY: Teacher's College Press. 
Copyright of Behavioral Development Bulletin is the property of Joseph D. Cautilli and its content may not be copied or emailed to multiple sites or posted to a listserv without the copyright holder's express written permission. However, users may print, download, or email articles for individual use. 